INTRODUCTION

\title{
Exposing Mr Butts' tricks of the trade
}

\section{K M Cummings, R W Pollay}

Tobacco Control 2002;11(Suppl I):i1-i4

$\mathrm{O}$ n 12 May 1994, an unsolicited box of what appeared to be tobacco industry documents was delivered to Professor Stanton Glantz at the University of California at San Francisco (UCSF). ${ }^{1}$ The return address on the box was listed as "Mr Butts". As it turned out, the box contained a collection of internal industry studies and reports that had been copied by a paralegal working for the law firm representing the Brown and Williamson Tobacco Company (B\&W). The paralegal, Dr Merrell Williams, had been hired in 1988 by the law firm of Wyatt, Tarrant and Coombs to review millions of pages of memoranda, reports, and research studies related to B\&W and their parent affiliate British American Tobacco (BAT). The goal of the exercise was to identify material that was perceived to be "critical" in terms of litigation risk for the company. Williams was laid off in 1992, but retained copies of thousands of pages of documents. The following year Williams, who had been a heavy smoker himself, was diagnosed with a serious heart ailment. He contacted the Wyatt firm and informed them that he had retained some of the documents and would return them. However, he blamed his heart condition on the stress induced by what he had read about smoking in those documents and threatened to sue the Wyatt firm for his health problems unless they settled. Instead, the Wyatt firm filed a civil action against Williams, for theft of the secret tobacco documents.

In 1995, Glantz and his colleagues published a series of articles in the Journal of the American Medical Association ${ }^{2-6}$ and then a book, Cigarette Papers, ${ }^{1}$ summarising what was learned from that box of documents and related documents then available from scattered other sources. These reports provided the first real glimpse into the inner workings of the tobacco industry and facilitated further document discovery in subsequent tobacco litigation. Glantz and his colleagues provided undeniable evidence that the tobacco companies recognised early on that cigarettes were addictive and clearly harmful to health. Publication of this material attracted the attention of public officials, attorneys, and even the President of the USA. Former President Clinton has commented that the published document summaries had influenced his decision to move forward with a proposal to regulate nicotine as an addictive drug and cigarettes and smokeless tobacco as drug delivery devices. ${ }^{1}$

\section{SECOND WAVE OF RESEARCH PAPERS}

This supplement to Tobacco Control provides the second wave of research papers based on tobacco industry documents. The papers presented in this issue are based on the approximately 33 million pages of tobacco industry documents released as part of a settlement agreement between the tobacco industry and the Minnesota attorney general's office stemming from lawsuit over payment of insurance claims for treatment of tobacco caused illnesses. ${ }^{7}$ Initially, these documents were available only in hard copy in a warehouse located in Minneapolis, Minnesota. As a result of the Master Settlement Agreement between the major tobacco companies and a consortium of state attorney's general the documents in the Minnesota Depository are also available through company sponsored websites on the internet via: http://www.tobaccoresolution.com or http://www.tobaccodocuments.com.

Recognising the importance of this unique new source of data, the National Cancer Institute (NCI) developed a Program Announcement to encourage the study and analysis of the tobacco industry documents in a wide variety of subject areas. The NCI Program Announcement has played a major role in stimulating research in this field. At present, NCI is funding about a dozen tobacco document research grants on topics ranging from environmental tobacco smoke to the design of less hazardous cigarettes; funding for this supplement to Tobacco Control and several of the research papers were made possible because of NCI support. Similarly, the Centers for Disease Control and Prevention (CDC) has sought to broaden access to the tobacco industry documents through mounting certain collections of documents on its website. In January 2001, the American Legacy Foundation provided a \$15 million grant to the UCSF library to create a permanent electronic collection of the tobacco industry documents.

This supplement to Tobacco Control focuses on what the tobacco documents teach us about how tobacco products are marketed. Because of this focus on marketing, these papers were peer reviewed by scholars trained in marketing, advertising, economics, and consumer behaviour, as well as by those working in tobacco control. The papers presented in this issue reveal that nothing in the marketing of tobacco products is left to chance by the tobacco industry. Summaries of elaborate industry studies provide insight into how the tobacco industry used marketing research to peddle a deadly product. The papers in this issue identify the importance of two key target markets of new smokers and concerned smokers, and cover a wide range of marketing

Abbreviations: BAT, British American Tobacco; B\&W, Brown and Williamson Tobacco Company; $\mathrm{NCl}$, National Cancer Institute; UCSF, University of California at San Francisco 
tactics to craft strategies to be effective against these target markets: the classic domains of product, price, and promotion, as well as other marketing tools such as packaging, product placement in cinema, public relations, and political lobbying to shape the regulatory environment within which their marketing operates. ${ }^{8}$

\section{MARKETING TO YOUTH}

The paper by Cummings and colleagues evaluates the tobacco industry's claim that the tobacco industry does not market its products to youth. ${ }^{9}$ The material presented in this paper should put to rest any debate over this question. Candid quotes from industry executives refer to youth as a source of sales and as fundamental to the survival of the tobacco industry. The documents reveal that the features of cigarette brands, packaging, and advertising were developed and manipulated specifically with the intent of appealing to beginning smokers.

Also on the youth marketing theme, the paper by Wayne and Connolly illustrate how product design and formulation is as much a part of the marketing mix as product placement and advertising. ${ }^{10}$ Wayne and Connolly describe the effort made in the 1980s and early 1990s by RJ Reynolds Tobacco Company to capture a larger share of the youth smoking market by reformulating Camel cigarettes to reduce harshness and irritation so as to make it more appealing to new smokers.

The paper by Chaloupka and colleagues examines the tobacco industry's use of price related marketing strategies to capture market share among more price sensitive younger smokers. ${ }^{11}$ Price related promotional efforts such as "buy one get one free" (or "BlGlF"), targeted sampling activities, and the use of "value added" promotions (for example, Camel Cash) were identified as a critical factor in the growth of RJR's Camel brand in the 1980s and 1990s. Similarly, the growth of Marlboro market share among teenagers in the 1990s appears to be the result of a decision made by Philip Morris in 1993 to reduce the price of Marlboro cigarettes by 40 cents per pack in order to "increase market share and grow long term profitability in a price sensitive market."12

The paper by Katz and Lavack analysed marketing documents in an effort to understand the tobacco industry's frequent use of bar promotions. ${ }^{13}$ Their review shows that such promotions are carefully planned and targeted to reach a young adult market. While one might expect that bar promotions would have no impact on teenage smokers, tobacco industry documents reveal that such promotions help communicate product brand information indirectly through a diffusion process. The bar promotions appear to be highly successful in increasing sales of particular brands. It turns out tobacco manufacturers recognised that recruiting younger adults to smoke their cigarette brand is an effective way to communicate to teens which brand is "in". Since teens aspire to be older and more mature than they are, younger adult smokers represent a valuable way to extend the advertising message to teenagers. ${ }^{14}$

The paper by Mekemson and Glantz describes efforts made by the tobacco industry to use the entertainment industry to promote cigarette smoking. ${ }^{15}$ The documents reveal that in the 1980s, each of the major cigarette companies had hired product placement firms to get their brands advertised on television and in the movies. These product placement firms placed products and signage in positive situations that were calculated to encourage viewers to use tobacco. Despite the claim that cigarette companies have discontinued product placements in movies, recent evidence suggests otherwise. ${ }^{16}$

\section{MARKETING THE "LIGHT" ILLUSION}

Based on the assumption that less tar would produce less cancer, public health authorities in the 1950s and 1960s encouraged smokers who persisted in smoking to switch to filtered and low tar cigarette brands. ${ }^{17}$ With the endorsement of low tar cigarettes by public health authorities, cigarette manufacturers increasingly devoted their marketing budgets to promote lower tar yield cigarettes, with the resulting effect being a steady increase in the market share for cigarette brands with lower machine measured tar deliveries. The paper by Pollay and Dewhirst provides a presentation and interpretation of the evidence pertaining to the tobacco industry's intent in developing and marketing filtered and low tar and nicotine cigarettes. ${ }^{18}$ Corporate documents show that advertisements of filtered and low tar cigarettes was intended to reassure smokers concerned about the health risks of smoking, and to give the "health concerned smoker" an alternative to quitting. The paper by Wakefield and colleagues describes how the cigarette industry employed pack designs and colour to communicate the impression of lower tar or milder cigarettes. ${ }^{19}$

Industry documents also reveal that the cigarette companies recognised the inherent deceptiveness of cigarette brands labelled as "Light" or "Ultra Light". ${ }^{20}$ While it is true that changes in cigarette design did result in a more than a $60 \%$ reduction in the machine measured average sales weighted tar levels for the USA since $1954{ }^{21}$ the illusion of less tar, proved to be just that-an illusion. ${ }^{22}$ For the past three decades, cigarette filter ventilation was the main design feature that resulted in lower machine measured tar yields. The paper by Kozlowski and O'Connor examines what the industry knew about cigarette filter ventilation and smoker compensation. ${ }^{23}$ Their review of corporate documents reveals that industry scientists recognised that cigarette filter ventilation would result in smokers taking bigger puffs and blocking vent holes to maintain nicotine delivery, and that smokers of Ultra Light cigarettes would likely increase their daily smoking intake to satisfy the body's need for nicotine. In other words, cigarettes would continue to sell, and cigarette smokers would continue to die at an undiminished rate.

\section{DEFECTIVE FILTERS}

The paper by Pauly and colleagues discusses another product feature and brings attention to a little known fact about cigarette filters-namely, that they are defective. ${ }^{24}$ In 1995, Pauly and his colleagues first published their seminal research showing that the cut surface of virtually all cigarette filters are contaminated with loose microscopic cellulose acetate filter fibres that have the potential to be ingested and inhaled during smoking. ${ }^{25}{ }^{26}$ If the cigarette's filter included charcoal, the filter tip would be further polluted with carbon particles. ${ }^{27}$ The tobacco industry response to Pauly's research was to deny that filter fibre "fall-out" occurred at all. However, the documents reviewed in the paper by Pauly and colleagues leave no doubt that the tobacco industry and Philip Morris in particular has known about the filter contamination problem for more than 40 years. ${ }^{24}$ Moreover, evidence is presented that shows that the tobacco industry has been negligent in testing the health risks associated with ingesting filter contaminants and implementing technologies that would correct or at least reduce the contamination problem.

\section{MANIPULATING PUBLIC OPINION AND POLICY}

The final two papers in this issue by Morley and colleagues ${ }^{28}$ and Cummings and associates ${ }^{29}$ offer accounts of how the tobacco industry has attempted to manipulate public policy and public opinion related to the marketing of tobacco products. The paper by Morley and colleagues provides an accounting of Tobacco Institute spending at the state level during the 1990s ${ }^{28}$ The findings from this study show that the Tobacco Institute hired lobbyists to represent them in every state in the USA and that the amount of money allocated for lobbying and special projects was highest in states that were the most active in implementing public health measures to reduce cigarette smoking. 
In January 1954, US tobacco manufacturers jointly sponsored an advocacy advertisement entitled "A Frank Statement to Cigarette Smokers" which appeared in 448 newspapers in 258 cities reaching an estimated 43245000 Americans. ${ }^{30}$ The advertisement questioned research findings implicating smoking as a cause of cancer, promised consumers that their cigarettes were safe, and pledged to support impartial research to investigate allegations that smoking was harmful to human health. The paper by Cummings and colleagues provides an analysis of the extent to which the promises made by the tobacco industry in the "Frank Statement to Cigarette Smokers" were fulfilled. ${ }^{29}$ This paper is very relevant to US tobacco liability litigation, since the Frank Statement has been a centerpiece of most such cases. The paper exposes the industry's bad faith from the very beginning of the smoking and health controversy, its failure to comply with promises made to the public thereafter, and the resulting misinformation among the consuming public.

\section{IMPLICATIONS FOR TOBACCO CONTROL}

Tobacco control practitioners would be wise to heed the old adage, "unless you learn from the mistakes of the past, you are doomed to repeat them". No doubt mistakes made by public health authorities in responding to the industry's marketing of filtered and low tar cigarettes could inform the contemporary discussion of tobacco harm reduction, with the industry's test marketing of numerous "lower risk" cigarettes and pseudo-cigarettes (for example, Eclipse, Accord).

The papers presented in this supplement to Tobacco Control illustrate how a careful analysis of corporate documents can be used to validate and inform the design of tobacco control strategies. For example, the industry documents confirm the observation that young people are especially sensitive to variations in the price of cigarettes. ${ }^{11}$ The documents also reveal that young smokers primarily select a brand because of its image, not price. ${ }^{9}$ Thus, while young smokers are price sensitive, they tend not to want to substitute a premium, image oriented brand for one whose main feature is its low price. To help reduce the conflict young smokers experience between price and imagery, tobacco companies have devised marketing strategies to add value to the higher priced premium brands that teenagers want. ${ }^{11}$ These strategies have included promotions such as buy one pack, get one free, the offer of gifts in return for used cigarettes packs, and packaging cigarettes into smaller more, affordable units (that is, 10 cigarettes per pack instead of 20). Presumably, restricting these types of marketing approaches would help discourage young people from smoking.

The industry documents also provide evidence for some new approaches to tobacco prevention. The studies contained in this issue illustrate how the industry's manipulation of product design features such as the package style and colour, the length and diameter of the cigarette, and the use of additives to make the smoke less harsh (that is, milder and smoother) are critically important to public health goals in tobacco control.[19] ${ }^{20}{ }^{24}$ The evidence showing how cigarette pack design and advertising can be manipulated to mislead smokers into thinking that certain cigarette brands are safer than others, reinforces the need for independent oversight and regulation of these two elements of the marketing mix. ${ }^{18} 19$

The tobacco industry has vehemently opposed and will likely continue to oppose meaningful efforts to regulate their marketing of tobacco products. ${ }^{28}{ }^{29}$ The corporate documents provide a clear message to public health officials and political leader: no matter what the tobacco industry says, their actions are motivated by one thing-greed. As far as the tobacco industry's behaviour is concerned, private profits always trump public health. ${ }^{31}{ }^{32}$ Much like the battle against terrorism, success in tobacco control will depend largely upon the quality of the intelligence information we have to predict

\section{Cover story}

Richard Pollay, the guest editor of this special issue, discovered the document appearing on the cover several years ago in the John W Hill papers at the Wisconsin State Historical Society archives, while researching the US industry's use of public relations. Hill was the founding senior partner of the preeminent Hill \& Knowlton public relations firm. This firm charted the industry's long standing "controversy" strategy, starting with the conspiratorial Plaza Hotel meeting in 1953 and the subsequent January 1954 "Frank Statement" advocacy advertisement.

As this now titled and highlighted, but otherwise unedited, cover memo from mid 1954 so clearly indicates in three of its four paragraphs, these public relations activities were deemed highly confidential. It is remarkable that so "sensitive" a document, and the many other related materials, would be filed by Mr Hill and then donated, shortly after the premier Surgeon General's report of 1964, to an archives where they would inevitably become public, albeit only in 1989 after many years of being kept sealed. Perhaps Mr Hill has moral qualms about the industry's propaganda effort and fully intended this ultimate disclosure. Given his obvious talents, this seems more likely than a presumption of a sloppy error on his part.

For details on the PR activities of this era, see: Pollay RW. Propaganda, puffing and the public interest: the scientific smoke screen for cigarettes. Public Relations Review 1990; 16(3):27-42.

the future actions of the tobacco industry. The tobacco industry documents have provided an unprecedented opportunity to understand the past motivations and methods of the industry so that the mistakes of the past do not have to be repeated. The only question that remains is whether public health practitioners will be able to utilise the knowledge gained about the marketing of tobacco products to effectively regulate and counter the industry's well researched and well financed efforts to maximise tobacco sales and hence profits.

\section{Authors' affiliations}

K M Cummings, Department of Cancer Prevention, Epidemiology \& Biostatistics, Roswell Park Cancer Institute, Buffalo, New York, USA

R W Pollay, Faculty of Commerce and Business Administration,

University of British Columbia, Vancouver, Canada

\section{REFERENCES}

1 Glantz SA, Slade J, Bero LA, et al. The cigarette papers. Berkeley, California. University of California Press, 1996.

2 Glantz SA, Barnes DE, Bero LA, et al. Looking through a keyhole at the tobacco industry: the Brown and Williamson documents. JAMA 1995:274:219-24.

3 Slade J, Bero LA, Hanaver P, et al. Nicotine and addiction: the Brown and Williamson documents. JAMA 1995;274:225-33.

4 Hanauer $\mathbf{P}$, Slade J, Barnes ED, et al. Lawyer control of internal scientific research to protect against products liability lawsuits: the Brown and Williamson documents. JAMA 1995;274:234-40.

5 Bero LA, Barnes ED, Hanauer P, et al. Lawyer control of external scientific research: the Brown and Williamson documents. JAMA 1995;274:241-7.

6 Barnes ED, Hanauer P, Slade J, et al. Environmental tobacco smoke: the Brown and Williamson documents. JAMA 1995;274:248-53

7 Malone RE, Balbach ED. Tobacco industry documents: treasure trove or quagmire? Tobacco Control 2000;9:334-8.

8 McCarthy EJ. Basic marketing: a managerial approach. Homewood, Illinois: Irwin, 1960.

9 Cummings KM, Morley C, Horan J, et al. Marketing to America's youth: evidence from corporate documents. Tobacco Control 2002;11/suppl l): i5-17.

10 Wayne GF, Connolly GN. How cigarette design can effect youth initiation into smoking. Camel cigarettes, 1983-93. Tobacco Control 2002; 11 (suppl I):i32-39. 
11 Chaloupka F, Cummings KM, Morley C, et al. Tax, price and cigarette smoking: evidence from the tobacco documents and implications for tobacco company marketing strategies. Tobacco Control 2002;11 (supp I):i62-72.

12 Philip Morris Companies, Inc, April 2, 1993 press release. Bates NO 2048188736

13 Katz SK, Lavack AM. Tobacco-related bar promotions: insights from tobacco industry documents. Tobacco Control 2002;11/supp I):i92-101.

14 Zollo P. Wise up to teens: insights into marketing and advertising to teenagers. Ithaca, New York: New Strategist Publications, 1995.

15 Mekemson C, Glantz SA. How the tobacco industry built its relationship with Hollywood. Tobacco Control 2002;11 (suppl I):i81-91.

16 Tickle JJ, Sargent JD, Dalton MA, et al. Favourite movie stars, their tobacco use in contemporary movies, and its association with adolescent smoking. Tobacco Control 2001;10:16-22.

17 US Senate. Hearings before the Consumer Subcommittee of the Committee on Commerce. Reviewing progress made toward the development and marketing of a less hazardous cigarette. Serial No. 90-52, August 23-25, 1967.

18 Pollay RW, Dewhirst T. The dark side of marketing seemingly "Light" cigarettes: successful images and failed fact. Tobacco Control 2002;11 (suppl I):i18-31

19 Wakefield M, Morley C, Horan J, et al. The cigarette pack as image: new evidence from tobacco industry documents. Tobacco Control 2002; 11 (suppl I):i73-80

20 Leavell NR. Low-tar lie. Tobacco Control 1999;8:433-6.

21 National Cancer Institute. The FTC cigarette test method for determining tar, nicotine, and carbon monoxide yields of US cigarettes: report of the $\mathrm{NCl}$ Expert Committee. Bethesda, Maryland: National Institutes of Health, 1996. (NIH Publication No 96-4028.)
22 Burns DM, Benowitz NL. Overview and summary, In: Smoking and Tobacco Control Monograph, 13: risks associated with smoking cigarettes with low machine-measured yields of tar and nicotine. Washington, DC: US Department of Health and Human Services, Public Health Service, National Institutes of Health. (in press).

23 Kozlowski LT, O'Connor R. Cigarette filter ventilation is a defective design because of misleading taste, bigger puffs, and blocked vents. Tobacco Control 2002:11 (suppl I):i40-50.

24 Pauly JL, Mepani AB, Lesses JF, et al. Cigarettes with defective filters marketed for 40 years: what Philip Morris never told smokers. Tobacco Control 2002;11(suppl I):i51-61.

25 Pauly JL, Allaart HA, Rodriguez Ml, et al. Fibers released from cigarette filters: an additional health risk to the smoker? Cancer Res 1995;55:253-8.

26 Pauly JL, Stegmeier SJ, Mayer AG, et al. Release of carbon granules from cigarettes with charcoal filters. Tobacco Control 1997;6:33-40.

27 Borowicz JS, Streck RJ, Pauly JL. Contamination of cigarette filters with cellulose acetate fibers and particles documented in studies of adult smokers. Proceedings of the Annual Meeting of the American Association for Cancer Research, New Orleans, Louisiana. March 28-April 1, 1998. Vol 39, page 336, 1998 [abstract 2293].

28 Morley C, Cummings KM, Hyland A, et al. Tobacco Institute lobbying at the state and local levels of government in the 1990s. Tobacco Control 2002;11 (suppl I): i 102-9.

29 Cummings KM, Morley C, Hyland A. Failed promises of the cigarette industry and its effect on consumer misperceptions about the health risks of smoking. Tobacco Control 2002;1 1 (suppl I): i 1 10-17.

30 Pollay RW. Propaganda, puffing and the public interest: the scientific smoke screen for cigarettes. Public Relations Review 1990;16:27-42.

31 Kluger R. Ashes to ashes: America's hundred-year cigarette war, the public health, and the unabashed triumph of Philip Morris. New York: Alfred A Knopf, 1996.

32 Kessler D. A question of intent: a great American battle with a deadly industry. New York: Public Affairs, 2001.

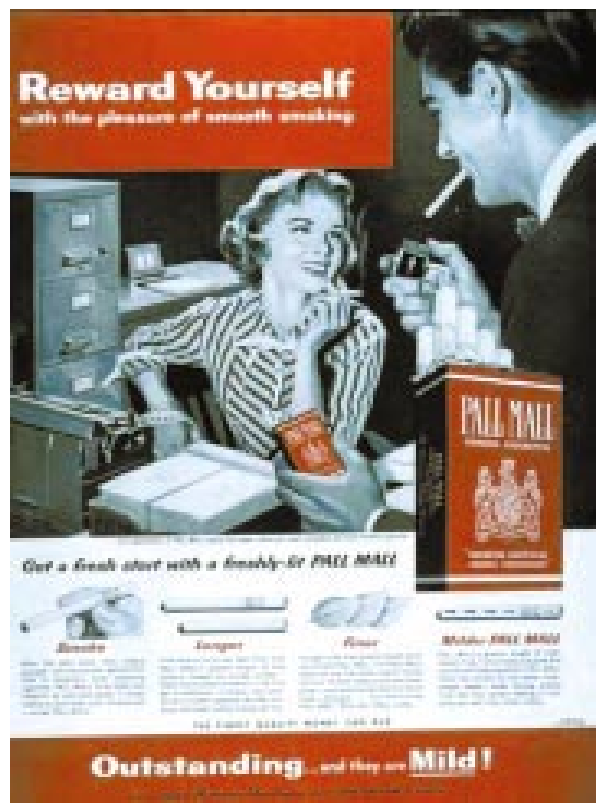

